\title{
Association between Psychological Wellbeing and Antiretroviral Therapy Adherence in North-Central, Nigeria
}

\author{
Modupe Oladunni Taiwo", Funmi-Togonu Bickersteth \\ Department of Psychology Obafemi Awolowo University, Ile-Ife, Nigeria \\ *Corresponding author: oladunnitaiwo@gmail.com
}

\begin{abstract}
Psychological wellbeing of antiretroviral patients in Nigeria is under researched despite being a critical success factor in ART adherence. Using a sample of antiretroviral therapy patients $(\mathrm{n}=641)$ from six clinics in North central Nigeria in a cross sectional mixed method approach, we examined the domain of psychological wellbeing that is associated with ART adherence. ART adherence was 88\%. Environmental mastery (84.4\%), Autonomy (73.2\%) and Self-acceptance (65.4\%) were associated with higher ART adherence. Among sociodemographic characteristics, only states of residence $\left(X^{2}=26.0841, p<.05\right)$ was significant. Cognitive behavioural therapy by a skilled psychologist is crucial for empowering ART patients to maintain optimal ART adherence.
\end{abstract}

Keywords: antiretroviral adherence, HIV/AIDS, north central Nigeria, psychological wellbeing

Cite This Article: Modupe Oladunni Taiwo, and Funmi-Togonu Bickersteth, "Association between Psychological Wellbeing and Antiretroviral Therapy Adherence in North-Central, Nigeria." American Journal of Applied Psychology, vol. 5, no. 1 (2017): 18-24. doi: 10.12691/ajap-5-1-4.

\section{Introduction}

In the last one decade, discourse about anti-retroviral therapy adherence has gained increased attention across the globe [35]. In the absence of cure for HIV and AIDS, Antiretroviral Therapy (ART) remains the only intervention for increasing life expectancy in infected persons [35]. ART has been found to successfully halt viral replication, increase CD4 cells and significantly reduced AIDS related morbidity and mortality [43]. ART also has a public health benefit of decreased transmission of an undetectable viral load [12].

Optimal adherence to antiretroviral drugs (ARV) dosage schedule and timing at a threshold of $95 \%$ or more is required to attain an undetectable viral level in infected persons $[28,31,34]$. Studies have reported the difficulties in attaining optimal adherence as people living with HIV/AIDS tend to miss doses or ignore nutrition recommendation [4]. These studies also opined that nonadherence to ART has implications for treatment failure, development of resistant HIV strains and increased risk of new infections among care givers.

Findings from various studies across the world have presented different levels of ART adherence, albeit higher in Africa compared to Europe and America [8,28,33]. Similarly, an earlier meta-analysis review of 28 North American and 27 Sub-Sahara African studies reported a pooled ART adherence estimate of $55 \%$ for North America and $77 \%$ for Sub-Sahara Africa (Mills et al, 2006). In confirmation of high ART adherence in Africa, Zuurmond [44], reported adherence levels of 90\%, 94\% and $88 \%$ in an evaluation of ART programs in Nigeria, Uganda and Zambia respectively. This is also consistent with Hardon et al, (2006) who reported 77\% in sub-Sahara Africa. Bailey, Oramasionwu, \& Wolf, [7], also noted that patient's failure in maintaining dose time and schedule contributed to poor adherence which was reported at $56.8 \%$. Some studies have also documented challenges facing AIDS patients in adhering to ART and its implications for multiple poor health outcomes such as drug resistance [4], high rate of relapse and rehospitalization [6], co-morbidities with other diseases [7], high mortality and increased global burden of the disease [11].

Although ART adherence studies have gained wide recognition in resource rich settings [5,9], studies in Africa have been dominated by Eastern and Southern African scholars. In West Africa however, ART studies have emphasized clinical indicators of ART adherence at the expense of non-clinical factors that have similar influence on ART adherence [1,17]. More so, the few studies that have used non-clinical indicators utilized few samples and thus, unable to generalize findings within a larger group [6].

Antiretroviral therapy program in Nigeria commenced in 2002 as an expanded response to AIDS epidemic (NACA, 2013). The program which started with treatment of 10,000 adults and 5000 children with a 3-drug ARV combination; 2 NRTI (lamivudine + stavudine) and 1 NNRT (nevirapine) has been expanded to reach over 750,000 persons in more than 473 centers across Nigeria [24]. Early stages of the ART program were plagued with structural and management challenges which negatively impacted on adherence by AIDS patients. A 
comprehensive literature search revealed that scientific study on ART adherence in Nigeria as an emerging field is dominated by the medical scientists. Only very few nonmedical scholars have shown interest in field of research. In addition, researches on ART adherence in Nigeria have not gained sufficient prominence as compared to other African nations such as South Africa and Uganda.

Some studies have identified psychological variables such as life satisfaction, happiness, depression, anxiety and quality of life as predictors of ART adherence $[16,17,22,30,39]$. These variables were stand alone and measured different components of psychological functioning in relation to ART adherence. Therefore, there is a paucity of research focusing on a holistic domains of psychological wellbeing in relation to ART adherence. This study therefore utilized a multi-dimensional psychological inventory to find out the association between psychological wellbeing and ART adherence as an important contribution to understanding psychology of health outcomes among people on HIV treatment.

\subsection{Theoretical Perspective: Psychological Wellbeing in Relation to ART Adherence}

The psychological well-being of a person has been described as the wellness and stability of that person's self. In the conceptualization of psychological wellbeing, theorists have presented two perspectives; short term (Subjective well-being or hedonic) and long term (psychological well-being or eudaimonic) to describe the psychological functioning of the individual. Early studies have described wellbeing as a subjective experience of happiness [41], a cognitive nature (Dierner, Suh, Lucas \& Smith, 1999) and a positive view of one's life [25].

Ryff [29] developed a complex and theoretically grounded view on wellbeing based on a combination of humanistic, clinical and life span developmental theories. This theoretical view conceived wellbeing as a multidimensional construct made up of six domains that described different attitudes to life. These are:

1. Self-acceptance, a positive attitude towards selfassessment of good or bad qualities.

2. Positive relations with others describes a warm, satisfying, trusting relationship with others.

3. Autonomy describes self-determination, independence and ability to resist social pressure to conform to certain societal norms that are at variance with ones' values.

4. Environmental mastery is being able to effectively maximize surrounding opportunities, choose or create a context suitable to personal needs and values.

5. Purpose in life indicates an individual's goal in life and a sense of directedness towards achieving such goals.

6. And finally, personal growth is the feeling of continued development, openness to new experiences and realization of one's potential.

This theory offered a holistic and value laden framework to understand the psychological wellbeing of individuals in the society. In understanding psychology of health outcomes, many studies have found association between psychological wellbeing and medication adherence in chronic illnesses [15,20,21,27]. For instance, Bravo, Edwards, Rollnick [10], Andersen, Magidson, O’Cleirigh, Remmert, Kagee et al., [5] and Elwyn, 2010) reported depression, mental illness, poor self-perception as psychological indicators of poor medication adherence in the treatment of cancer patients.

Early theorists have described the role of psychological wellbeing in influencing behavioural outcomes from different perspectives. Some of these include Maslow [23] conception of self-actualization, Rogers (1961) view of the fully functioning person, Jung's [18] formulation of the individuation, and Allport (1961) conception of maturity. On a general note, these theories underpins and explains individual's reactions and preferences for accepting a new behaviour and particularly those that relates to health care. People living with HIV/AIDS are disposed to expressing either positive or negative emotions that is capable of influencing attitude towards antiretroviral adherence.

The objectives are therefore to describe and access the relationship between socio-demographic characteristics and ART adherence and to establish the association between domains of psychological wellbeing on ART adherence.

\section{Method}

\subsection{Study Location}

The study was conducted in six secondary level public health facilities selected from three states in North Central zone, Nigeria. Among the six geo-political zones in Nigeria, the North Central zone was selected for this study due to its consistently high HIV prevalence of $7.5 \%$ or more from 2010 to 2012 and being among the top 10 states with high HIV prevalence in 2015 [24]. These health facilities among others participated in the expanded ART access at no cost to PLHIV in 2006 supported by international donors. The facilities have qualified personnel and standard diagnostic laboratory to support minimal laboratory services required prior to initiating ART.

\subsection{Study Design}

This study employed a cross-sectional descriptive survey design, which used a mixed method of quantitative and qualitative approaches to collect data simultaneously to triangulate information received for a robust reporting of findings. In recognition of the sensitive nature of this study and the need to assure confidentiality, the researcher worked through the National Network of People Living with HIV/AIDS in Nigeria (NEPWAN), and community based organizations providing HIV/AIDS care and support services in each of the states to reach the respondents. Members of the PLHIV network were trained as research assistants to administer the questionnaires.

\subsection{Population and Sample}

In recognition of the varying population of people accessing ART from the treatment sites, after determining 
the sample size using Cochran formula $\mathrm{n}=\frac{\mathrm{z}^{2} \mathrm{pq}}{\mathrm{d}^{2}}=\frac{1.96^{2} \times 0.5 \times 0.5}{0.05^{2}}=384$. A $20 \%$ refusal $/$ nonparticipation was added to become 461 .

Which sets standard normal deviation at 1.96, with best guess of adherence prevalence at $50 \%$ and $\alpha$ level of 0.05 , the proportion of samples randomly selected from each ART site added up the survey sample. A total of $461 \mathrm{HIV}$ patients who consented were recruited for the study between June and August 2015. In addition, 20\% of the survey respondents were purposively selected and participated in the focus group discussion. Altogether, twelve FGDs with homogenous groups who were divided by age (16-24 years and <25 years and sex (M, F) were conducted in the three ART sites. Each focus group discussion had 8 participants and was conducted for 45 mins in a spare room within the health institutions. There was a moderator and a note taker, responses were also captured by a tape recorder upon the groups' consent to ensure no information was lost.

\subsection{Data Collection Instrument}

For the quantitative data, two main research instruments were used. The first was a 30 item standardized psychological wellbeing inventory with 5-point Likert scale developed by Ryff [29] measuring the 6 domains of psychological wellbeing. The second was a 24-item existing questionnaire that collected self-reported information from the people living with HIV/AIDS about their drug adherence pattern in terms of dosage schedule and timing over a seven day period. The questionnaire generated responses about the socio-demographic characteristics, the number of pills prescribed and the number of pills taken in the last seven days.

Qualitative data was generated through a focus group discussion guide with five themes; knowledge and attitude about ART, adherence pattern, support for adherence, disclosure of HIV status and understanding interaction of psychological wellbeing with ART adherence. There was a group facilitator and a note taker to moderate and document discussions consecutively. Consent of group members was sought prior to tape recording of the discussion. The group discussion provided in-depth information on the perception about ART adherence and how it is moderated by psychological wellbeing. Probe questions were also asked where necessary to further clarify the views expressed by the focused group participants.

\subsection{Ethical Clearance and Consent}

Ethical clearance for this study was obtained from the Research and Ethical Committee of Public Health Department of Obafemi Awolowo University, Ile-Ife. Informed written consent was obtained from each participant before engaging in the research.

\subsection{Data Analysis}

Quantitative data were analyzed using STATA 13. Descriptive statistical tests were employed including frequencies and chi-square. Thematic and ethnographic summary analysis was conducted on the qualitative data from the focus group discussion. This also involved verbatim quotations from participants to further buttress certain arguments raised during the discussion.

\section{Results}

Four hundred and sixty-one (461) PLHIV receiving ART from the six sites selected from three states in North Central, Nigeria were studied. Two hundred and forty-five participants (53\%) were recruited from Benue, 100 (22\%) from the Federal capital territory and 116 (25\%) from Nassarawa in proportion to the population of ART patients in each site. The ages of these participants ranged from 10 to 65 years with a mean age of 36 years. The participants had been on ART programme for a period ranging from 6 months to 5 years with $40 \%$ receiving ART between 3-5 years.

As shown in Table 2, majority of respondents were females (64\%). The gender distribution reflects the national statistics on the predominance of females over males who are living with HIV/AIDS in Nigeria. In terms of marital status, half (50.1\%) of respondents were married. Interestingly, the distribution of religion showed predominantly Christianity $\mathbf{( 7 5 . 3 \% )}$ as the common religion practiced considering that, North-Central Nigeria is predominantly Muslim community. Almost all the respondents, (95\%) had been to school. Among the educated ones, $48.6 \%$ had secondary education and $33.1 \%$ had tertiary education. Less than half of respondents (39.9\%) engaged in private employment and (19.7\%) were civil servants. Economic status of respondents varied and majority (41.2\%) are low income earners, at less than N50, 000 monthly income, while very few (2\%) earn quite high income between N200, 000 and N250, 000.

Table 1. Distribution of samples across ART study sites

\begin{tabular}{|c|c|c|c|c|}
\hline SN & States & ART Facilities & Population & Sample selected per ART site \\
\hline 1 & \multirow[b]{2}{*}{ Benue } & Gboko General Hospital & 5,369 & 111 \\
\hline 2 & & Kastina-Ala General Hospital & 6,588 & 134 \\
\hline 3 & \multirow{2}{*}{ FCT } & Asokoro General Hospital & 2,541 & 52 \\
\hline 4 & & Wuse General Hospital & 2,364 & 48 \\
\hline 5 & \multirow{2}{*}{ Nassarawa } & Yanyan general Hospital & 2,174 & 44 \\
\hline 6 & & Obi General Hospital & 3,545 & 72 \\
\hline & & Total & 22,581 & 461 \\
\hline
\end{tabular}

${ }^{1}$ Benue: Gboko General Hospital and Kastina-Ala General Hospital Federal Capital Territory: Wuse General Hospital, Abuja and Asokoro General Hospital Nassarawa: Yanyan General Hospital and Obi General Hospital. 
Table 2. Socio-demographic distribution of respondents $n=461$

\begin{tabular}{|c|c|c|}
\hline Variables & Frequency & Percentage $\%$ \\
\hline \multicolumn{3}{|l|}{ States } \\
\hline Benue & 245 & 53.2 \\
\hline FCT & 100 & 21.7 \\
\hline Nassarawa & 116 & 25.2 \\
\hline \multicolumn{3}{|l|}{ Gender } \\
\hline Male & 168 & 36.0 \\
\hline Female & 293 & 64.0 \\
\hline \multicolumn{3}{|l|}{ Age Group } \\
\hline$<20$ & 7 & 1.5 \\
\hline $20-29$ & 83 & 18.0 \\
\hline $30-39$ & 217 & 47.1 \\
\hline $40-49$ & 129 & 28.0 \\
\hline$>49$ & 25 & 5.4 \\
\hline \multicolumn{3}{|l|}{ Marital status } \\
\hline Married & 231 & 50.1 \\
\hline Single/never married & 135 & 29.3 \\
\hline Widowed & 39 & 8.5 \\
\hline Separated & 37 & 8.0 \\
\hline Divorced & 19 & 4.1 \\
\hline \multicolumn{3}{|l|}{ Religion } \\
\hline Christianity & 274 & 75.3 \\
\hline Islam & 109 & 23.6 \\
\hline Traditional & 2 & 0.4 \\
\hline No religion & 3 & 0.7 \\
\hline \multicolumn{3}{|l|}{ Monthly income } \\
\hline 200,000- 250,000 & 9 & 2.0 \\
\hline $150,000-200,000$ & 5 & 1.1 \\
\hline $100,000-150,000$ & 27 & 5.9 \\
\hline $50,000-100,000$ & 72 & 15.6 \\
\hline Less than 50,000 & 190 & 41.2 \\
\hline No income & 158 & 34.3 \\
\hline \multicolumn{3}{|c|}{ Length of years on ART } \\
\hline Above 5 years & 156 & 34.1 \\
\hline 3-5 years & 186 & 40.3 \\
\hline $1-2$ years & 100 & 21.7 \\
\hline 6 months & 18 & 3.90 \\
\hline
\end{tabular}

Among the socio-demographic variables explored, only state showed association between psychological wellbeing and ART adherence $\left(\mathrm{X}^{2}=26.0841, \mathrm{P}>.001 \mathrm{CI}=3\right.$. 4; 213.7). In ranking the domains of psychological wellbeing in terms of their association with ART adherence, three of the six domains showed association that was above average: Environmental mastery 84.39\%, Autonomy $73.17 \%$ and purpose in life $65.37 \%$.

\subsection{Qualitative Results}

Perceptions about psychological wellbeing is diverse and dynamic. ART patients' perceived their emotions, beliefs and a lifetime on medication as concerns that induced psychological problems. Other issues of poor adherence include; high pill burden, sever illness, poor patients-caregivers' relationship and feelings of neglect and disconnection from the society.

"I think it is about the way we feel and our emotions about the sickness, If you allow these things to bother you, it might affect the drug you are taking because too much worry can affect you negatively. But when you put away worries, it helps you to adhere to your drugs and stay healthy” (Adult Male, FGD 001)

PLHIV perceived that positive psychological wellbeing is crucial to ART adherence and subsequently good health outcome. 'Positive psychological status can be stimulated when we are happy and nothing is making us sad, especially when we have a job and get money to take care of ourselves, taking ARVs will be easier'’. (Youth Male, FGD 004)

"it feels good to be well, if we our emotions are stable and we are accepted by our friends and families. We will have good psychological status and this will in turn improve our adherence to ARVs. But at the moment it is not easy" (Adult Female, FGD 003)

ART patient linked psychological problems with ability to secure a job and a stable source of income to improved livelihood and access to recommended nutrition.

"Many of us do not have jobs to do, I think the PLHIV will become psychologically stable if they have a means of income that will support the nutrition recommended for ARV effectives”. (Youth Female, FGD 012).

\section{Optimal ART adherence}


Figure 1. Showing levels of ART adherence in relation to Positive wellbeing 
Table 3. Association of socio-demographic characteristics with ART adherence

\begin{tabular}{|c|c|c|c|c|}
\hline Characteristics & Optimal & Sub-optimal & $X^{2}$ (p-value) & uOR \\
\hline \multicolumn{3}{|l|}{ State } & \multirow{4}{*}{$\begin{array}{c}26.0841 \\
(0.000)\end{array}$} & \multirow{4}{*}{$\begin{array}{c}26.7 \\
\text { (3. } 4 ; 213.7)\end{array}$} \\
\hline Benue & 57.3 & 19.6 & & \\
\hline FCT & 20.0 & 35.3 & & \\
\hline Nassarawa & 22.7 & 45.1 & & \\
\hline \multicolumn{3}{|l|}{ Sex of respondent } & \multirow{2}{*}{$\begin{array}{l}2.0016 \\
(0.157)\end{array}$} & \\
\hline Female & 87.3 & 12.6 & & \\
\hline \multicolumn{3}{|l|}{ Marital status } & \multirow{6}{*}{$\begin{array}{l}1.1809 \\
(0.881)\end{array}$} & \multirow{6}{*}{$\begin{array}{c}1.92 \\
(0.80 ; 4.63)\end{array}$} \\
\hline Single/never married & 29.0 & 31.4 & & \\
\hline Married & 49.8 & 52.9 & & \\
\hline Separated & 8.3 & 5.9 & & \\
\hline Divorced & 4.4 & 1.9 & & \\
\hline Widowed & 8.5 & 7.8 & & \\
\hline \multicolumn{3}{|l|}{ Religion } & \multirow{4}{*}{$\begin{array}{l}3.3435 \\
(0.188)\end{array}$} & \multirow{4}{*}{$\begin{array}{c}0.49 \\
(0.2 ; 1.02)\end{array}$} \\
\hline Islam & 23.2 & 31.4 & & \\
\hline Christianity & 76.3 & 66.7 & & \\
\hline Traditional & 0.5 & 1.9 & & \\
\hline \multicolumn{3}{|l|}{ Education } & \multirow{5}{*}{$\begin{array}{c}6.1766 \\
(0.10)\end{array}$} & \multirow{5}{*}{$\begin{array}{c}1.02 \\
(0.11 ; 9.43)\end{array}$} \\
\hline Quranic & 3.2 & 2.0 & & \\
\hline Primary & 15.4 & 16.0 & & \\
\hline Secondary & 47.5 & 64.0 & & \\
\hline Higher & 33.9 & 18.0 & & \\
\hline \multicolumn{3}{|l|}{ Monthly income } & \multirow{5}{*}{$\begin{array}{l}3.3186 \\
(0.651)\end{array}$} & \multirow{5}{*}{$\begin{array}{c}0.7 \\
(0.09-11.03)\end{array}$} \\
\hline $200,000-250,000$ & 2.0 & 2.0 & & \\
\hline $50,000-100,000$ & 15.9 & 13.1 & & \\
\hline Less than 50,000 & 42.2 & 33.3 & & \\
\hline No income & 33.2 & 43.1 & & \\
\hline \multicolumn{3}{|c|}{ Length of years on ART } & \multirow{5}{*}{$\begin{array}{l}2.9111 \\
(0.406)\end{array}$} & \multirow{5}{*}{$\begin{array}{c}0.3 \\
(0.17 ; 0.90)\end{array}$} \\
\hline Above 5 years & 33.7 & 41.2 & & \\
\hline 3-5years & 41.7 & 29.4 & & \\
\hline $1-2$ years & 20.7 & 25.5 & & \\
\hline 6 month & 4.0 & 3.9 & & \\
\hline
\end{tabular}

Some of the participants made a few suggestions for promoting the psychological status of PLHIV as an important factor for enhancing ART adherence. A participant suggested that:

"The need to fight against stigma and discrimination, build the capacity of PLHIV for improved livelihood, provide quality counseling, promote family-based care and provide emotional support is important for promoting ART adherence”. (Adult female, 010).

Quality assurance of the supply chain management should be maintained to prevent stock out of drugs and consumables. Diagnostic equipment especially for viral load testing need to be functional to ensure timely conduct of necessary laboratory test including early infant diagnosis for adequate care.

"Another thing that Government need to do is to repair all the broken CD4 and viral load machines because for a long time we have not been taking viral load test for us to know where we are with the virus". (Adult Male, FGD 009).

\section{Discussion and Conclusion}

Defaulting from the treatment regimen is one of the most important problems in managing HIV/AIDS. The outcomes of poor adherence are treatment failure, development of drug resistant strains of HIV and potential interference with future therapeutic options [35]. The key finding from this study was that three out of the six domains of psychological wellbeing; autonomy, environmental mastery and purpose in life showed association with high levels of ART adherence. Autonomy is described as independence and can be explained by selfdetermination theory. Ntoumanis et al; [26] associated it with intrinsic motivation for self-directed behaviour towards a positive health outcome. In this study, PLHIV who are autonomous were motivated towards ART adherence. Environmental mastery is the ability to effectively maximize surrounding opportunities, choose or create a context suitable to personal needs and values. PLHWA in the study probably seized the opportunity of a 
free diagnostic care, free ARVs and other support services to enhance their ART adherence and subsequently gained control of their lives. Purpose in life indicates an individual's goal in life and a sense of directedness towards achieving such goals. PLHWA who achieved optimal ART adherence are likely to have set certain goals and targets for themselves. The desire to attain these goals might be an explanation for the motivation for ART adherence.

Furthermore, the finding is also consistent with Duong, et al., [13] who concluded that patients' psychological factors are essential to medication acceptance and adherence. Similarly, in agreement with Adegoke et al., [1] who among other factors noted that patients' sense of worth and acceptance of HIV status largely promotes medication adherence. The findings agrees with Cohen et al., [12] and Fawzi et al., [16] that positive attitude towards good medication adherence is a product of the belief that such medication can improve health outcome. It also corroborated Kretchy et al., [20] who asserted that positive mental health status of patients predicts optimal medication adherence. However, it contradicts Vian, DeSilva, Cabral, Williams, Gifford et al., [38] who reported strong association between autonomous motivation and competence among low adherers in China.

There were more females (64\%) participants in this study. This proportion of females agrees with the national surveillance report that women are twice the number of men in HIV/AIDS infected population in Nigeria [24]. Furthermore, cultural and economic factors that increased the vulnerability of women to HIV infection could also account for this difference [42]. Majority (75.1\%) were in the age group 30-49 years. This is consistent with findings that these age group are at higher risk of HIV infection [35] because they are sexually active and within reproductive age group. Half of the study participants were currently married. The distribution of marital status is important as heterosexual transmission accounts for $80 \%$ of HIV transmission in Nigeria [24].

A significant proportion of participants either have no income or are low income earners. This poor socio-economic status was also reported in the focus group discussion where many have called on the government to provide livelihood support through job creation and skill acquisition schemes for improved socio- economic status and good quality of life. The overall adherence level in the study group was $88 \%$. This adherence level is consistent with other findings in African countries such as Uganda 94\%, Zambia 88\% and Kenya 77\% [44], 80\% in Senegal [32], and $87 \%$ in Jos, Nigeria [33], but contradicts $48 \%$ in Niger Delta [11], 44\% in Ife-Ijesha zone [2].

The plausible reason for the high level of adherence among the study group may be explained by a number of factors. Firstly, PLHWA received free laboratory investigations and free ARVs as a result of international donor support for scaling up ART in Nigeria. Another reason could also be the psychosocial support received through the support group structure where PLHWA meet periodically to discuss issues relating to ART adherence and other personal issues.

The finding that demographic characteristics are not statistically associated with ART adherence in this study other than Benue state agrees with [19], who only found that age of respondent is the only demographic characteristics that is significant with ART adherence. However, findings contradicts [40] who found association between education and ART adherence

In conclusion, adherence to ART is a complex psychosocial behaviour and is a function of several factors which defines how well adjusted an ART client is to attain optimal ART adherence. Health Policy Makers, Care providers, Government and International donor community need to appreciate the contribution of psychological functioning to medication adherence. Psycho-education which promotes emotional, cognitive and behavioural wellbeing is therefore required as core content of ART program guideline to improve ART adherence among the defaulters. Professional mental health care on a need basis for PLHIV should be integrated in the ART service minimum package to provide information and resources for promoting positive psychological functioning.

\section{Acknowledgements}

Consortium for Advanced Research Training in Africa (CARTA). CARTA is jointly led by the African Population and Health Research Center and the University of the Witwatersrand and funded by the Wellcome Trust (UK)(Grant No: 087547/Z/08/Z), the Department for International Development (DfID) under the Development Partnerships in Higher Education (DelPHE).

\section{Authors' Contribution}

Modupe Taiwo- The article is a component of her $\mathrm{PhD}$ work and she was responsible for the conceptualization, design, data collection and analysis. She also developed and produce the article.

Funmi Togonu-Bickersteth - She was the $\mathrm{PhD}$ supervisor and provided guidance and review of content at every stage of development.

\section{References}

[1] Adegoke, O. A., \& Zerish, Z. N. (2013). The complex nature of adherence in the management of HIV/AIDS as a chronic medical condition. Diseases (1), 18-35.

[2] Afolabi M.O., Ijadunola K.T., Fatusi A.O \& Olasode OA. (2009). Determinants of adherence to antiretroviral drugs among people living with HIV/AIDS in the Ife-Ijesa zone of Osun state, Nigeria. African Journal of Primary Health Care and Family Medicine. 1(1), Art. \#6, 6 pages.

[3] Allen, C., Simon, Y., Edwards, J., \& Simeon, D. (2011). Adherence to antiretroviral therapy by people accessing services from non-governmental HIV support organizations in three Caribbean countries. West Indian Medical Journal. 60(3), 269-275.

[4] Alvarez-Uria, Naik, Pakam and Midde. (2013). Factors associated with attrition, mortality, and loss to follow up after antiretroviral therapy initiation: data from an HIV cohort study in India. Glob Health Action, 6, 21682.

[5] Andersen, Magidson, O’Cleirigh, Remmert, Kagee et al., (2016). A pilot study of a nurse-delivered cognitive behavioral therapy intervention (Ziphamandla) for adherence and depression in HIV in South Africa. J Health Psychol.

[6] Aransiola, J., Imoyera, W., Olowookere, S., \& Zarowsky, C. (2014). Living well with HIV in Nigeria? Stigma and survival 
challenges preventing optimum benefit from an ART clinic. Global Health Promotion.

[7] Bailey, S. C., Oramasionwu, C. U., \& Wolf, M. S. (2013). Rethinking Adherence: A Health Literacy-Informed Model of Medication Self-Management. Journal of Health Communication, 18(sup1), 20-30.

[8] Baltazary, G., Akarro, R. R., \& Mussa, A. S. (2011). Some factors associated with non-adherence to antiretroviral therapy (ART) in people living with HIV/AIDS (PLHA) in Tanzania: a case study of Dar es Salaam region. East African Journal of Public Health, 8(4), 237-246.

[9] Bere, Nyamayaro, Magidson, Chibanda, Chingono et al., (2016). Cultural adaptation of a cognitive-behavioural intervention to improve adherence to antiretroviral therapy among people living with HIV/AIDS in Zimbabwe: Nzira Itsva. Journal of Health Psychology.

[10] Bravo, P., Edwards, A., Rollnick, S., \& Elwyn, G. (2010). Tough decisions faced by people living with HIV: a literature review of psychosocial problems. AIDS Review, 12(2), 76-88.

[11] Chijioke, A.N., Osaro, E., Oseikhuemen A.E, \& Chris. I. A. (2006). Adherence to ART among HIV-Infected Subjects in a Resource-Limited Setting in the Niger Delta of Nigeria. Africa Journal Health Science; 13: (3-4) 13-17.

[12] Cohen, Chen, McCauley, Gamble, Hosseinipour et al., (2016). Antiretroviral Therapy for the Prevention of HIV-1 Transmission. New England Journal of Medicine.

[13] Duong, Piroth, Grappin, Forte, Peytavin et al., (2015). Evaluation of the Patient Medication Adherence Questionnaire as a tool for self-reported adherence assessment in HIV-infected patients on antiretroviral regimens. HIV clinical trials.

[14] Edward, J. M., Jean, B. N., Iain, B., James, O., Amir, A., Sonal, S., \& David, R. B. (2009). Adherence to Antiretroviral Therapy in Sub-Saharan Africa and North America: A Meta-analysis. American Medical Association, 296(6), 679-690.

[15] Efficace, Breccia, Cottone, Okumura, Doro et al., (2016) Psychological well-being and social support in chronic myeloid leukemia patients receiving lifelong targeted therapies. Journal of Supportive Care in Cancer, 1-8.

[16] Fawzi, Ng, Kanyanganzi, Kirk, Bizimana et al., (2016). Mental Health and Antiretroviral Adherence Among Youth Living With HIV in Rwanda. Pediatrics, e20153235.

[17] Houston, Mikrut, Guy, Fominaya, Tatum et al; (2016). Another look at depressive symptoms and antiretroviral therapy adherence: The role of treatment self-efficacy. Journal of Health Psychology, 21(10), 2138-2147.

[18] Jung, C.G. (1964). Man and his Symbols, New York, N.Y.: Anchor Books, Doubleday.

[19] Kambai Avong, van Wyk, Njab, Abimiku, Ndembi et al.,(2015). Adherence to Anti-Retroviral Therapy in North Central Nigeria. Current HIV research, 13(4), 268-278.

[20] Kretchy, Owusu-Daaku and Danquah. (2014). Mental health in hypertension: assessing symptoms of anxiety, depression and stress on anti-hypertensive medication adherence. International journal of mental health systems, 8(1), 1.

[21] Liu, Floud, Pirie, Green, Peto et al., (2016). Does happiness itself directly affect mortality? The prospective UK Million Women Study. The Lancet, 387(10021), 874-881.

[22] Maiese, Johnson, Bancroft, Goolsby Hunter and Wu. (2016). Quality of Life of HIV-infected Patients Who Switch Antiretroviral Medication Due to Side Effects or Other Reasons. Current Medical Research and Opinion, 1-24.

[23] Maslow, A. H. (1968). Toward a Psychology of Being. New York: D. Van Nostrand Company

[24] NACA report (2015). accessed in July 2016 from https://naca.gov.ng/article/hiv-epidemic-nigeria.

[25] Neugarten, B. L., Havighaurst, \& Tobin, S. S. (1968). "Personality and Patterns of Aging”. In Neugarten (Ed.), Middle Age and Aging (pp. 173-180). Chicago: University of Chicago press.
[26] Ntoumanis, Thøgersen-Ntoumani, Deci, Ryan et al., (2012). Selfdetermination theory applied to health contexts a meta-analysis. Perspectives on Psychological Science, 7(4), 325-340.

[27] Okely and Gale. (2016). Well-being and chronic disease incidence: The English longitudinal study of ageing. Psychosomatic Medicine, 78(3), 335.

[28] Reda, A., Biadgilign, and Sibhatu. (2012). Determinants of Adherence to Antiretroviral Therapy among HIV-Infected Patients in Africa. AIDS Research and Treatment, 1-8.

[29] Ryff, C. D., \& Keyes, C. L. M. (1995). The structure of psychological well-being revisited. Journal of Personality and Social Psychology, 69, 719-727.

[30] Sauceda, Wiebe and Simoni. (2016). Childhood sexual abuse and depression in Latino men who have sex with men: Does resilience protect against nonadherence to antiretroviral therapy? Journal of Health Psychology, 21(6), 1096-1106.

[31] Schaecher, K. L. (2013). The importance of treatment adherence in HIV. American Journal of AIDS Management and Care, 19 (12 Suppl), s231-237.

[32] Sow, Toure, Coume, Dia and Traore. (2012). Predictors of ART adherence among HIV infected individuals in Dakar Senegal. Journal of Medicine and Medical Sciences, 3(4), 212-216.

[33] Taiwo, Idoko, Welty, Otoh, Job et al., (2010). Assessing the viorologic and adherence benefits of patient-selected HIV treatment partners in a resource-limited setting. JAIDS Journal of Acquired Immune Deficiency Syndromes, 54(1), 85-92.

[34] UNAIDS (2011) Political Declaration on HIV/AIDS; 2011, available at:

http://www.unaids.org/en/aboutunaids/unitednationsdeclarationsan dgoals/2011highlevelmeetingonaids/.

[35] UNAIDS (2013). 'Global Report: UNAIDS Report on the Global AIDS Epidemic. Retrieved in June 2015 from http://www.unaids.org/en/media/unaids/contentassets/documents/e pidemiology/2.

[36] UNAIDS, World Health Organization and UNICEF. Epidemiological fact sheets on HIV/AIDS and sexually transmitted infections in Nigeria [homepage on the Internet]. 2004 Available from: http://data.unaids.org/ Publications/FactSheets01/nigeria_en.pdf.

[37] UNDP Human Development Report (2013): accessible from http://hdrstats.undp.org/en/countries/country_fact_sheets/cty_fs_N GA.html.

[38] Vian, DeSilva, Cabral, Williams, Gifford et al., (2016). The role of motivation in predicting antiretroviral therapy adherence in China. Journal of Health Psychology, 1359105316672922.

[39] Vo, Hoffman, Nash, El-Sadr, Tymejczyk et al.,(2016). Gender Differences and Psychosocial Factors Associated with Quality of Life Among ART Initiators in Oromia, Ethiopia. AIDS Behaviour, $1-10$.

[40] Wanjohi. (2009). Factors that influence non-adherence to antiretroviral therapy among HIV and AIDS patients in Central Province, Kenya. A research thesis submitted in partial fulfillment of the requirement of Degree of Master of Public Health (Epidemiology and Disease Control) in the School of Health Sciences of Kenyatta University.

[41] Watson, D., Clark, L.A., \& Tellengen, A. (1988). Development and Validation of brief measures of positive and negative affect: the PANAS Scales. Journal of personality and Social Psychology, 54, 1063-1070.

[42] WHO (2010). 'Towards Universal Access: Scaling up priority HIV/AIDS interventions in the health sector'. Accessed on 5 February 2013 from www.avert.org.

[43] WHO (2013, June) 'Global update on HIV treatment 2013: Results, Impact and Opportunities', accessed in June 2015 from http://www.avert.org/universal-access-hivtreatment.htm\#footnote1_d7kzm9s.

[44] Zuurmond. E.B. (2008). Adherence to ARVs-Challenges and successes. A consultation with CAFOD partners and members of the Catholic HIV and AIDS Network (CHAN), 5(3), 8. 